\title{
Case report: Patient controlled analgesia after pediatric scoliosis surgery through erector spinal plane catheter
}

\section{Analgesia controlada por paciente a través de catéter en plano erector espinal poscirugía escoliosis pediátrica}

\author{
Carlos Largo Pineda ${ }^{1,2, *}$, Leonardo Cendales Poveda ${ }^{1,3}$, Andrea Pérez Pradilla ${ }^{1}$ \\ Department of Anesthesia, Instituto de Ortopedia Infantil Roosevelt. Bogotá, Colombia. \\ 2 Department of Anesthesia, Universidad Militar Nueva Granada. Bogotá, Colombia. \\ 3 Department of Anesthesia, Clínica la Colina. Bogotá, Colombia.
}

Conflict of interest: The authors declare no conflict of interest.

Funding: No funding for this research was gived to the authors.

Fecha de recepción: 28 de junio de 2020 / Fecha de aceptación: 11 de septiembre de 2021

\begin{abstract}
Introduction: Erector spinae plane block (ESPB) is a recently described technique (2016); its use as continuous analgesia with an intrafascial catheter in anterior scoliosis surgery for pediatric patients in intensive care unit (ICU) has not been reported in the literature. Objective: To describe the use of an intrafascial catheter in the erector spinae for continuous infusion and patient-controlled analgesia as a postoperative analgesic technique in anterior scoliosis surgery. Clinical Case: 15-year-old patient weighing $34 \mathrm{~kg}$, diagnosed with scoliosis with $110^{\circ} \mathrm{Cobb}$ angle in the context of neurofibromatosis, subjected to anterior corrective surgery with continuous analgesia and patient-controlled analgesia through an intrafascial catheter in the erector spinae. Conclusions: The use of continuous intrafascial analgesia and patient-controlled analgesia in the erector spinae provided adequate analgesic control in the postoperative period of corrective anterior scoliosis surgery in a pediatric patient in ICU.
\end{abstract}

Key words: Analgesia, patient-controlled, erector spinae plane block, scoliosis.

\section{RESUMEN}

Introducción: El bloqueo del plano del erector de la espina (ESPB) es una técnica de reciente descripción (2016). Su uso como analgesia continua con catéter intrafascial en cirugía de escoliosis por vía anterior para pacientes pediátricos en unidad de cuidados intensivos ( $\mathrm{UCI}$ ) no ha sido reportado en la literatura. Objetivo: Describir el uso del catéter intrafascial del erector de la espina como técnica analgésica posoperatoria en cirugía de escoliosis vía anterior con analgesia en infusión continua y controlada por el paciente. Caso clínico: Paciente de 15 años, peso $34 \mathrm{~kg}$, con diagnóstico de escoliosis con ángulo de Cobb $110^{\circ}$ en el contexto de neurofibromatosis, sometido a cirugía correctiva vía anterior con analgesia continua y controlada por el paciente mediante catéter intrafascial en erector de la espina en UCI. Conclusiones: El uso de analgesia intrafascial continua y controlada por el paciente por catéter en el erector de la espina resulta en un adecuado control analgésico posoperatorio de cirugía correctiva de escoliosis via anterior en un paciente pediátrico en UCI.

Palabras clave: Analgesia, controlado por el paciente, bloqueo del plano del erector de la espina, ultrasonido, escoliosis. 


\section{Introduction}

T he word "scoliosis" (derived from the Greek word "scolios", which means crooked, and the suffix-sis, which denotes action) indicates sideways curvature and/or dynamic and aesthetic deformity of the spine[1]. However, in medical science, this term refers to an abnormal curvature of the spine that deviates more than 10 degrees from its normal axis at rest[1]. The etiology of scoliosis, despite being idiopathic in countless cases, has also been related to different disorders, including congenital diseases. Neurofibromatosis type 1 is a known genetic condition that mainly affects the development and growth of neuronal cells, coexisting with some degree of scoliosis in up to $60 \%$ of cases, predominantly in the thoracic segment[2],[3].

As part of treatment, various surgical strategies have been developed and proposed for anterior, posterior or mixed approaches, depending on the objectives of the intervention and on the evidence. Open thoracotomy is described as a severely painful procedure[4]; therefore, to relieve pain from the posterior approach, neuraxial anesthesia and analgesia techniques using an epidural catheter have been implemented, apparently with excellent results[5],[6]. However, the data that support the use of regional analgesic techniques through an anterior surgical approach remain scarce.

Erector spinae plane block (ESPB) is an analgesic technique described for acute and chronic, lateral and dorsal, anterior chest pain control, regardless of etiology[7]. Thanks to its multiple benefits, this technique has been indicated for postoperative pain management in an increasing range of pediatric surgeries[8]-[12]. Nevertheless, the use of this technique for continuous infusion and patient-controlled analgesia (PCA) using a local anesthetic infusion pump in pediatric patients subjected to corrective anterior scoliosis surgery has not been reported to date.

We report the case of a patient with a history of neurofibromatosis type 1 subjected to initial anterior corrective scoliosis surgery with unilateral ESPB and continuous analgesic infusion and PCA in the postoperative period.

\section{Case} ther.

An informed consent form was signed by the patient's fa-

A male patient, 15 years of age, weighing $34 \mathrm{~kg}$, with a history of neurofibromatosis type 1 was referred for initial corrective anterior scoliosis surgery for thoracic scoliosis (cobb angle of approximately $110^{\circ}\left(67^{\circ}\right.$ cervical and $32^{\circ}$ lumbar)) (Figure 1).

The patient was monitored according to recommendations from the American Society of Anesthesiologists for invasive monitoring (invasive blood pressure, urinary output, and evoked potential neuromonitoring).

The procedure involved intravenous anesthetic induction (2 mg midazolam, $100 \mathrm{mg}$ propofol, $150 \mathrm{mcg}$ fentanyl and $30 \mathrm{mg}$ rocuronium), orotracheal intubation and placement of a central venous catheter and of an arterial line; the total intravenous technique (propofol and remifentanil) was used for anesthesia maintenance. Left thoracotomy was performed, followed by resection of the sixth and seventh costal margins and T7 and T8

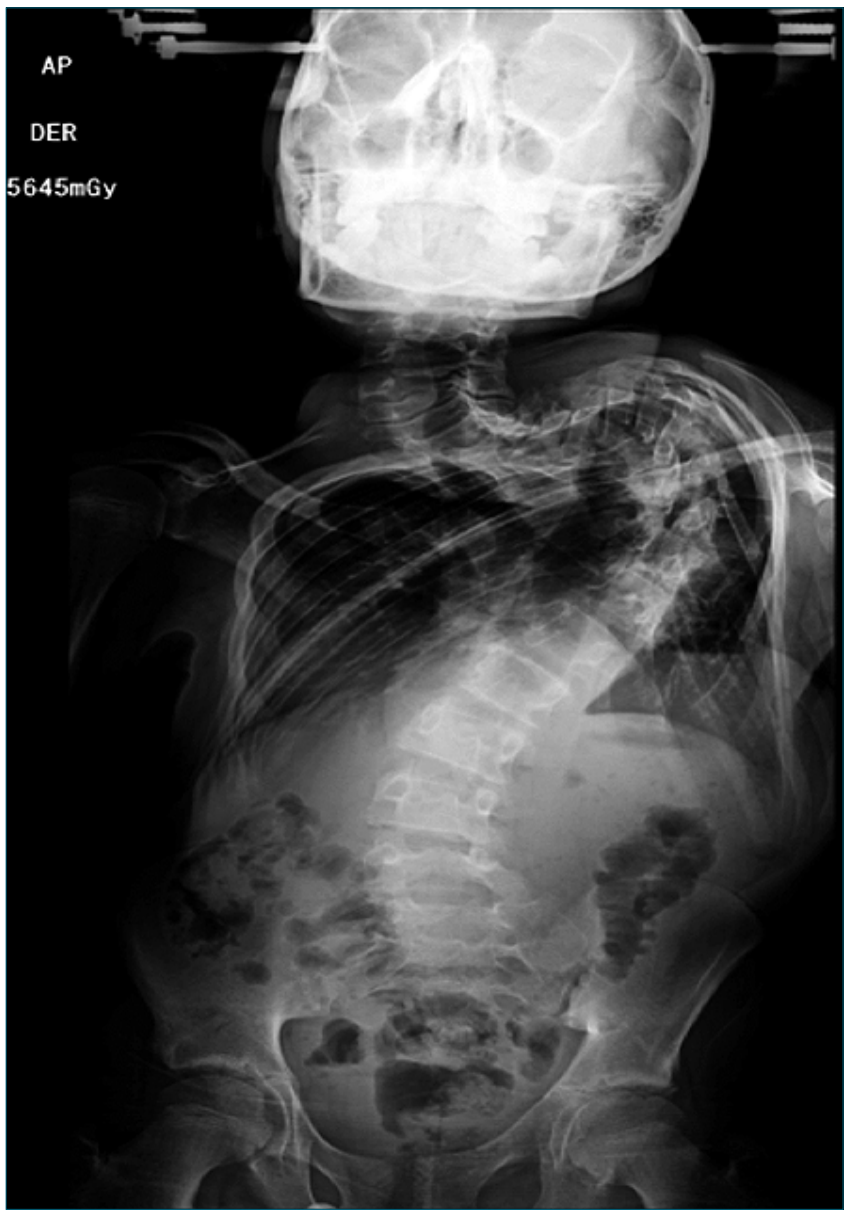

Figure 1. AP radiograph, Cobb thoracic vertebral angle $110^{\circ}$. Source: Author.

corpectomy using an ultrasonic scalpel, in a surgical time of 8 hours.

At the end of the procedure and with the patient in the right lateral decubitus position, ESPB was performed using a 6-13 MHz linear transducer (Ultrasound System Sonosite ${ }^{\circledast}$ MTURBOO). After identifying the T5 transverse process, (Figure 2 A), in-plane approach was performed with a Tuohy needle $18 \mathrm{G}$ and with hydrolocalization towards the ultrasound target. Once the needle tip was in the erector spinae plane an epidural catheter (Portex ${ }^{\circledR}$ ) 19G was moved forward, fixing it at a depth of $3 \mathrm{~cm}$ (Figure $2 \mathrm{~B}$ ). Under direct ultrasound visualization and after aspiration without blood, $30 \mathrm{cc}$ of $0.25 \%$ bupivacaine with 1:400,000 epinephrine was infused. After completing the procedures, the patient was extubated and transferred to the Pediatric Intensive Care Unit without complications, with a score -1 on the Richmond Agitation-Sedation Scale (RASS) and an 8/10 Aldrete score. The patient was transferred to the intensive care unite for postoperative surveillance.

The postoperative multimodal analgesic plan in ICU included infusion of $0.1 \%$ bupivacaine at a rate of $8 \mathrm{cc} /$ hour per catheter. In addition, $600 \mathrm{mg}$ metamizole was administered every 8 hours with intravenous morphine exclusively as a rescue dose of $1.5 \mathrm{mg}$, with a maximum of 6 doses in 24 hours in case of 


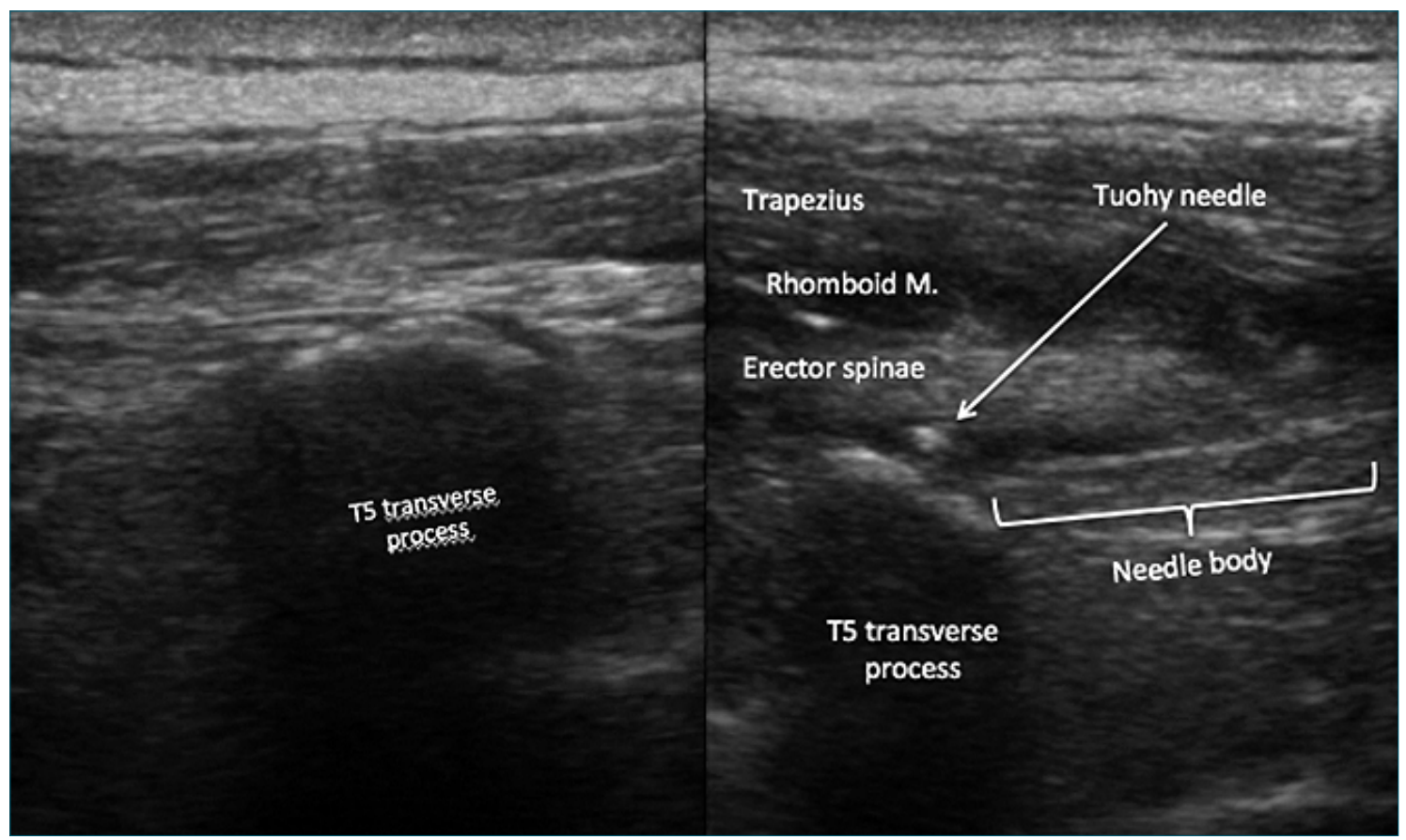

Figure 2. Transverse process T5. Tip of the catheter on T5 Transverse process. Source: Author.

breakthrough pain.

After completing the procedure and at every 2 hours for the first 12 hours, pain intensity was monitored using the VAS (Visual Analogue Scale). The first rescue analgesia was requested at 6 hours due to a VAS pain intensity of 70/100 mm, which reduced pain to 40/100 $\mathrm{mm}$ after $5 \mathrm{~min}$. Subsequently and given the request for a second rescue morphine dose, at 8 hours of monitoring, a bolus of $10 \mathrm{mg}$ of $0.1 \%$ bupivacaine was administered via catheter in the ESP for a VAS pain intensity of 80 $\mathrm{mm} / 100 \mathrm{~mm}$, which was reduced by $37.5 \%$ (from $80 \mathrm{~mm} / 100$ $\mathrm{mm}$ to $30 \mathrm{~mm} / 100 \mathrm{~mm}$ ), After this doses by clinical examination we found an area of diminished sensation to pinprick extending from $\mathrm{T} 2$ to $\mathrm{T} 8$ in a cephalocaudad direction, and from a line $2 \mathrm{~cm}$ lateral to the thoracic spine to the midclavicular line in an anterior-posterior direction.

Therefore, infusion through the ESP catheter was increased to $9 \mathrm{cc} /$ hour. At 24 hours and after quantifying VAS $70 / 100$ $\mathrm{mm}$, a rescue bolus of $10 \mathrm{mg}$ of $0.1 \%$ bupivacaine was administered again, with reprograming of the infusion strategy $(9 \mathrm{cc}$ hour) and PCA through intermittent boluses with three-hour block doses, administered by the patient if he needed an analgesia rescue (10 $\mathrm{ml}$ bolus of the same mixture).

Patient progression remained stable, without new spikes of pain or requirements for additional doses of opioid rescue analgesia. A VAS score of $40 / 100 \mathrm{~mm}$ was reported at 48 hours, and after a VAS report of 20/100 $\mathrm{mm}$ at 72 hours, the catheter was removed, with no complications. The patient went to the general hospitalization room on the third postoperative day and was discharged tow weeks later. The patient continues in orthopedic control every 6 months, no long-term complications were identified.

\section{Discussion}

ESPB was first described in 2016 by Forero and colleagues in patients with thoracic neuropathic pain secondary to thoracotomy interventions[7]. In the pediatric population, ESPB has been reported as an alternative for acute postoperative pain control in very painful procedures, such as thoracic surgery[13],[14], chest wall tumor resection[11] and thoracotomy for cardiothoracic surgery[8] and for patients who refuse to receive other analgesic techniques[10] or even for surgeries outside the rib cage[12],[15].

ESPB was performed for postoperative analgesic management of a double corpectomy by thoracotomy for initial anterior scoliosis surgery. In this case, ESPB not only led to a satisfactory resolution of the pain intensity associated with such an extensive and invasive surgery but also made it possible to control the incidental pain in a practical way and according to a patient-controlled analgesia technique, that is, simultaneous administration of infusion through the regional catheter and PCA through intermittent boluses of local anesthetic with three-hour block times. No adverse effects or complications were associated with this technique.

With this technique we could avoid neuroaxis approach (with epidural catheter), since anatomical disposition is manipulated and modified in the surgical act, this may leave the patient at greater risk of neuroaxis injuries and infectious complications of the surgical area. Additionally, the presentation of adverse effects secondary to the administration of opioids such as ileus, nausea and pruritus is prevented.

To date, no optimal doses or ideal volumes have been reported for this block in the pediatric population. However, some authors have reported the effective administration of vol- 
umes ranging from 14 to 30 cc of analgesic mixture[9],[10]. In the present case, after administering an initial dose of $30 \mathrm{cc}$ and setting anesthesia maintenance at $8 \mathrm{cc} / \mathrm{h}$, analgesic efficacy was only achieved for approximately 6 hours. Subsequently, analgesic control improved after increasing continuous infusion to $9 \mathrm{cc} / \mathrm{h}$ and after including patient-controlled intermittent boluses of local anesthetic, with three-hour block doses.

\section{Conclusion}

The use of ESPB as an analgesic technique for local anesthesia through continuous infusion and PCA provided adequate analgesic control in the postoperative period of corrective anterior scoliosis surgery in a pediatric patient in ICU.

\section{List of abbreviations}

ESPB: Erector spinae plane block.

PCA: Patient controlled analgesia.

RASS: Richmond Agitation-Sedation Scale.

\section{Declarations}

Ethics approval and consent to participate

Institutional ethics approval was emitted by ethics Roosevelt institute committee telephone number +57 13534016 .

\section{Consent for publication}

Written informed consent was gathered from the patient's father for publication of this Case report.

\section{Authors' contributions}

CLP contributed to collection of data and writing the manuscript. LCP and APP contributed to performing of anesthesia and revising the manuscript. All authors read and approved the final manuscript.

\section{Acknowledgments}

Department of Anesthesiology, Instituto de Ortopedia Infantil Roosevelt, Bogotá, Colombia. for his contributions to providing tools and conditions to develop this case.

\section{References}

1. Konieczny MR, Senyurt $H$, Krauspe R. Epidemiology of adolescent idiopathic scoliosis. J Child Orthop 2013 Feb;7(1):3-9.

2. Chong KL, Lam KS, Zuki Z. Dystrophic Scoliosis in Neurofibromatosis and Rib-head Resection: A Case Report. Malays Orthop J. 2017 Nov; 11(3):59-62.

3. Tsirikos Al, Saifuddin A, Noordeen MH. Spinal deformity in neurofibromatosis type-1: diagnosis and treatment. Eur Spine J. 2005 Jun;14(5):427-39.

4. Rullander A, Jonsson $H$, Lundstrom M, Lindh V, Young People's Experiences With Scoliosis Surgery. Orthopaedic Nursing, 2013 Nov-Dic; 32(6):327-33.

5.. Borgeat A, Blumenthal S. Postoperative pain management following scoliosis surgery. Current Opinion in Anaesthesiology 2008 Jun; 21:313-316.

6.. Sundarathiti $P$, Pasutharnchat $K$, Jommaroeng $P$. Thoracic epidural-general analgesia in scoliosis surgery. J Clin Anesth. 2010 Sep;22(6):410-4.

7. Forero M, Adhikary SD, Lopez H, Tsui C, Chin LJ. The erector spinae plane block: a novel analgesic technique in thoracic neuropathic pain. Reg Anesth Pain Med. 2016 Sep-Oct; 41(5):6217.

8. Wong J, Navaratnam M, Boltz G, Bilateral continuous erector spinae plane blocks for sternotomy in a pediatric cardiac patient. Journal of Clinical Anesthesia 47 (2018) 82-83.

9. De la Cuadra-Fontaine JC, Concha M, Vuletin F, Arancibia H. Continuous Erector Spinae Plane block for thoracic surgery in a pediatric patient. Paediatr Anaesth. 2018 Jan;28(1):74-5.

10. Ueshima $\mathrm{H}$, Otake $\mathrm{H}$. Clinical experiences of erector spinae plane block for children. J Clin Anesth [Internet] [Internet]. 2018; 44(October 2017); 41.

11. Muñoz F, Cubillos J, Bonilla AJ, Chin KJ. Erector spinae plane block for postoperative analgesia in pediatric oncological thoracic surgery. Can J Anaesth. 2017 Aug;64(8):880-2.

12. Chin KJ, Adhikary S, Sarwani N, Forero M. The analgesic efficacy of pre-operative bilateral erector spinae plane (ESP) blocks in patients having ventral hernia repair. Anaesthesia. 2017 Apr;72(4):452-60.

13.. Bhoi D, Acharya P, Talawar P,Malviya A. Continuous erector spinae plane local anesthetic infusion for perioperative analgesia in pediatric thoracic surgery SJA. 2018 Jul-Sept;12 (3): 502-3.

14. Kaplan I, Jiao Y, AuBuchon JD, Moore RP. Continuous Erector Spinae Plane Catheter for Analgesia After Infant Thoracotomy: A Case Report. A\&A Practice. 2018 Nov; 11(9):250-2.

15. Thomas DT, Tulgar S. Ultrasound-guided Erector Spinae Plane Block in a Child Undergoing Laparoscopic Cholecystectomy. Cureus. 2018 Feb; 10 (2):1-3. 